\title{
Overall Anatomic Severity and Prognosis in Patients Presenting with, or Requiring a Major Lower Limb Amputation from Civilian Trauma
}

\author{
Sanchez-Arteaga Alejandro", Lusilla-Lopez Alejandro, Zarain-Obrador Leire, Burneo- \\ Esteves Mauricio, Rey-Valcarcel Cristina, Perez-Diaz $M^{a}$ Dolores and Turegano-Fuentes \\ Fernando
}

University General Hospital Gregorio Marañón, Universidad Complutense de Madrid, Spain

*Corresponding author: Sanchez-Arteaga Alejandro, General Surgery Department, Universidad Complutense de Madrid, Spain, E-mail: alejandros.arteaga@gmail.com

\section{Introduction}

Trauma is one of the most frequent mechanisms causing limb amputation [1]. However, major limb amputations are rare in the civilian population, the largest numbers being seen in the military, often caused by explosive devices [2], and are considered to have, in general, a poorer prognosis, needing more aggressive treatments [1].

There is evidence of wide-ranging variations in outcome following major lower limb trauma [3], with a substantial proportion of patients experiencing longterm disability. Studies in civilian trauma have demonstrated the importance of maintaining maximum length and performing infracondileal amputations rather than supracondileal, reporting better physical quality of life [4]. Unlike the military, the causes of lower limb amputation in the civilian population are diverse, often stemming from traumas resulting in multiple injuries, many of them life-threatening [1,5]. Lower limb amputations have been the topic of several studies by the military [2], but, to our knowledge, only one study has focused on the civilian population [5].

Our main aim, using data from the Severe Trauma Registry from University Hospital Gregorio Marañón, Madrid, Spain (level I civilian hospital), was to assess whether the overall anatomic severity, and prognosis, of patients with lower limb amputation is comparable to that reported by the military.

\section{Material and Methods}

Data came from the Severe Trauma Registry of a level I civilian hospital, and one of the few referral hospitals for polytraumatized patients in Madrid, between 1993 and 2015. Only patients who were admitted with a lower limb amputation, or a mangled extremity requiring an amputation were included. Foot amputations were excluded. No mangled-extremity scores were used in the decision as to whether to proceed with completion of the amputation or try to save the limb in patients with a severely mangled extremity. Associated pelvic fractures were classified according to the Tile classification [6].

Patient data collected included mechanisms of injury, other injuries in cases of multiple injuries, Abbreviated Injury Scale (AIS), Injury Severity Score (ISS), New Injury Severity Score (NISS), extremity and non-extremity related morbidity according to the Clavien-Dindo classification [7], mortality, and ICU and hospital length of stay (LOS).

For statistical analysis between mechanisms of injury with NISS/ISS values, associated injuries, LOS and mortality, categorical variables were compared utilizing Fisher's exact test. SPSS statistics v.21 software was used in the analysis.

We reviewed the literature regarding mechanisms of injury, treatment details, morbidity, and outcomes. A search of indexed articles was made on PubMed, and 
Table 1: Features of patients with LLA (foot amputation is excluded) from our registry.

\begin{tabular}{|l|l|}
\hline Features & Patients \\
\hline $\begin{array}{l}\text { Gender } \\
\text { Male }\end{array}$ & 16 \\
Female & 18 \\
\hline Mean Age & 44 \\
\hline Mechanisms of injury & \\
$\quad$ Train run-over & 9 \\
Pedestrian run-over & 8 \\
MVC & 5 \\
Occupational accidents & 5 \\
Falls from height & 5 \\
GSW & 1 \\
Bomb explosion & 1 \\
\hline Level of amputation & \\
Infracondileal & 20 \\
Supracondileal & 14 \\
\hline Urgent amputation & 31 \\
\hline Delayed amputation & 3 \\
\hline
\end{tabular}

MVC: Motor Vehicle Collision; GSW: Gunshot Wound; LLA: Lower Limb Amputation.

Table 2: Comparison of overall severity and prognosis with that reported from the military.

\begin{tabular}{|c|l|l|}
\hline & $\begin{array}{l}\text { Study report } \\
(\mathbf{n}=\mathbf{3 4})\end{array}$ & $\begin{array}{l}\text { Military trauma } \\
(\mathbf{n}=\mathbf{7 2 0})[2]\end{array}$ \\
\hline Mean Age & 44 & 23 \\
\hline $\begin{array}{c}\text { Amputation } \\
\text { Single }\end{array}$ & 27 & 494 \\
Double & 7 & 191 \\
Triple & 0 & 32 \\
Quadruple & 0 & 3 \\
\hline Median ISS & 26 & 24 \\
\hline ICU days & 15 & 6.6 \\
\hline LOS & 73 & 26.4 \\
\hline Mortality & $4(11.7 \%)$ & $44(6.1 \%)$ \\
\hline
\end{tabular}

ISS: Injury Severity Score; ICU days: Length of Stay in Intensive Care Units; LOS: Length of Stay.

the search terms used were: "major limb AND amputation", "civilian AND trauma", "traumatic AND amputation" and "military AND amputation". We also reviewed large series of amputations in military trauma, analyzing the overall anatomic severity and the reported mortality.

\section{Results}

Thirty-four patients were admitted with a major traumatic LLA (Lower Limb Amputation) out of 2430 trauma-related admissions (0.013\%). Median age was of 44 years (IQ interquartile (IQR) range 28-64). Age differences by sex or mechanisms of injury were not observed. In decreasing order, the mechanisms were: 17 run-overs (9 train run-overs, all resulting from suicide attempts), 5 motor vehicle collision (MVC), 5 occupational accidents with limb wound, 5 falls from a height, 1 gunshot wound (GSW), and 1 bomb explosion during the Madrid, March 11, 2004 terrorist attacks.

Of the 34 cases, seven presented with, or under-
Table 3: Morbidity of patient with traumatic major LLA (foot amputation is excluded).

\begin{tabular}{|l|l|l|}
\hline Complication & $\begin{array}{l}N^{\circ} \\
\text { patients }\end{array}$ & $\begin{array}{l}\text { Clavien-Dindo } \\
\text { classification }\end{array}$ \\
\hline Non-related to stump & $\mathbf{1 4}$ & \\
Acute renal failure & 4 & II-IV \\
\hline Respiratory infection & 3 & IV \\
Catheter-related infection & 2 & II \\
Urinary tract infection & 1 & II \\
Meningitis & 1 & IV \\
Surgical site infection & 2 & III-IV \\
By-pass obstruction & 1 & III \\
\hline Related to stump & $\mathbf{2 1}$ & \\
Stump infection & 13 & II-III \\
Stump necrosis & 6 & III \\
Skin graft necrosis & 2 & III \\
\hline
\end{tabular}

Clavien-Dindo classification: I: Any desviation from the normal postoperative course; II: Requiring farmacological treatment; III: Requiring surgical, endoscopic or radiologic intervention; IV: Requiring intermediate care/UCI management; V: Death.

went, a bilateral LLA. Features of patients with LLA included in the study are shown in Table 1 . There were more patients who suffered an infracondileal amputation (20 patients) than supracondileal (14 patients). For 3 patients, an attempt was made to preserve the initial limb with revascularization. Patients with infracondileal amputations had lower ISS (median 22) compared to supracondileal amputations (median 33), but the latter had higher morbidity and mortality. Overall median ISS and NISS were 26 (IQR 17-34) and 34 (IQR 19-34), respectively. Table 2 shows a comparison of demographics, overall anatomic severity, and outcomes of our study with the biggest military registry of lower limb amputations to date [2].

Angioembolization was required in 4 patients with pelvic fracture because of acute hemorrhage, and 3 of them had a type $C$ fracture. Six of eleven patients with associated abdominal injuries underwent laparotomy for bleeding control. The 3 patients with brain contusion had a Glasgow Coma Scale (GCS) < 8 on arrival, but none of them died. There were 6 patients who had simultaneous thoracic, abdominal and pelvic injuries, and only one of them died. The cause of death was related to the severity of the pelvic fracture (type C). Upon hospital admission, 9 patients had hemorrhagic shock due to bleeding from more than one source. No acute abdominal bleeding was described as the main cause of shock.

$88.3 \%$ of the patients presented complications, $35 \%$ of it not associated to the stump wound, and $12 \%$ of patients died within 30 days of their injury. Regarding patients with stump wound complications, all of them required at least one more surgical procedure, and $25 \%$ of them needed multiple procedures for debridement, covering of the stump defect with flap/skin graft, or reamputation. Complications in accordance with the Clavien-Dindo classification are detailed in Table 3 and Table 4. 
Table 5 shows differences between train run-over and other mechanisms.

Those whose traumatic amputations were the result of a train run-over (Table 5) had an overall anatomic severity similar to other patients. They suffered a wide range of other injuries such as thoracic lesions, ribs fractures and pelvic fractures. The incidence of bilateral amputation was much higher than with other mechanisms. None of these patients died, as compared to the others mechanisms, their median ICU LOS was lower, but had a higher hospital LOS. Four of them were admitted to the ED in hypovolemic shock. Table 6 shows associated injuries, their anatomic severity and treatment performed.

\section{Discussion}

Traumatic lower limb amputations are a significant source of injury in war conflicts [2], and long series of patients have been published describing blasts as the

Table 4: Grading of the Clavien-Dindo classification.

\begin{tabular}{|l|l|}
\hline Clavien-Dindo classification & $\mathbf{N}=\mathbf{3 1}$ \\
\hline $\begin{array}{l}\text { Grade I - Any desviation from the normal } \\
\text { postoperative course. }\end{array}$ & 0 \\
\hline $\begin{array}{l}\text { Grade II - Requiring farmacological treatment. } \\
\text { Grade III - Requiring surgical, endoscopic or } \\
\text { radiologic intervention. }\end{array}$ & 4 \\
\hline $\begin{array}{l}\text { Grade IV - Requiring intermediate care/UCl } \\
\text { management. }\end{array}$ & 21 \\
\hline Grade V - Death. & 2 \\
\hline
\end{tabular}

most common mechanism [2]. On the other hand, published research on traumatic limb amputations related to civilian trauma are rare [5]. The only similar mechanism causing lower limb amputations (LLA) in civilians is explosions from terrorist attacks; many of these never reach the hospital alive [1].

Table 5: Differences between the train run-over and other mechanisms*.

\begin{tabular}{|c|c|c|c|}
\hline & Train Run-over & Other & $p$ \\
\hline Number of patients & 9 & 25 & \\
\hline Mean Age & $41 y$ & $47 y$ & \\
\hline Male & 3 & 13 & \\
\hline Female & 6 & 12 & \\
\hline ISS/NISS & $26 / 33$ & $26 / 34$ & N.S \\
\hline \multicolumn{4}{|c|}{ Associated injuries: } \\
\hline Thoracic & 5 & 10 & N.S \\
\hline Abdominal & 0 & 11 & 0.016 \\
\hline Pelvic & 2 & 8 & N.S \\
\hline Brain trauma & 1 & 4 & N.S \\
\hline $\begin{array}{l}\text { Bilateral } \\
\text { amputation }\end{array}$ & 5 & 2 & 0.02 \\
\hline \multicolumn{4}{|l|}{ LOS: } \\
\hline $\mathrm{ICU}$ & 13 & 16 & N.S \\
\hline Hospital & 103 & 63 & N.S \\
\hline Mortality & 0 & $4(16 \%)$ & N.S \\
\hline
\end{tabular}

LOS: Length of Stay; N.S: Not Significant; "Other mechanisms include: Pedestrian run-over, motor vehicle collision (MVC), occupational accidents, falls from a height, gunshot wound (GSW), and bomb explosion.

Table 6: Other injuries, anatomic severity, and treatment.

\begin{tabular}{|c|c|c|c|}
\hline Other injuries & $\mathrm{N}^{\circ}$ patients & AIS-85 & Treatment \\
\hline Thoracic: & 15 & & \\
\hline Pneumothorax & 7 & 3 & Chest tube \\
\hline Hemothorax & 5 & 3 & Chest tube \\
\hline Lung contusion & 7 & 3 & Medical \\
\hline Bronchial injury & 1 & 4 & Surgery \\
\hline Destruction thoracic wall & 1 & $\begin{array}{l}3 \\
\text { Mean: } 3.2\end{array}$ & Chest tube \\
\hline Abdominal: & 11 & & \\
\hline Retroperitoneal hematoma & 4 & 3 & Conservative/Surgery \\
\hline Bladder rupture & 4 & 3 & Surgery \\
\hline Kidney injury & 3 & 3 & Surgery \\
\hline Splenic hematoma & 1 & 3 & Surgery \\
\hline Liver laceration & 1 & 2 & Conservative \\
\hline Mesenteric injury/tear & 1 & $\begin{array}{l}2 \\
\text { Mean: } 3.2\end{array}$ & Conservative \\
\hline Pelvic Fracture: & 10 & & \\
\hline Type A & 4 & 2 & Conservative \\
\hline Type B & 3 & 3 & Conservative/AE \\
\hline Type C & 3 & $\begin{array}{l}4 \\
\text { Mean: } 3\end{array}$ & $A E$ \\
\hline Brain Injury: & 5 & & \\
\hline Brain contusion & 3 & 3 & Conservative \\
\hline Subarachnoid hemorrhage & 1 & 3 & Conservative \\
\hline Subdural hematoma & 1 & $\begin{array}{l}3 \\
\text { Mean: } 3\end{array}$ & Conservative \\
\hline
\end{tabular}

AIS-85: Abbreviated Injury Scale (1985 classification); AE: Angioembolization. 
When we compare our results with the traumatic amputation from IEDs in the military $[2,8]$, the overall anatomic severity was similar (median ISS of 26 vs. 24 , respectively). Nonetheless, ICU and hospital LOS (6.6 and 26.4 days in the military registry), as well as overall mortality were considerably higher in our study $(6.1 \%$ vs. $11.4 \%$ in our series). Whether this is the result of the overall injuries, or higher AIS, we cannot say, since the overall ISS is similar to that reported in the largest series of LLA in combat [2].

Trauma-related amputations represent an important source of permanent impairment, and functional limitation, causing not only physical but psychological and vocational consequences $[9,10]$. Studies have reported differences between civilian and military lower limb amputations regarding ISS/NISS and LOS [3]. There is a significant difference in kinetic energy between improvised explosive devices (IEDs) blasts and road traffic collisions (RTC); therefore, the severity and characteristics of these injuries are different. In contrast with previous studies [5,11-13], our results show that the most common mechanism of LLA in the civilian population was subway train run-over with $9(26.4 \%)$ patients, and pedestrian run-over, with $8(23.6 \%)$ patients. These results are consistent with the data from the National Trauma Databank [12].

With respect to associated injuries no differences were found between those due to train run-over and other mechanisms, with the exception of the absence of abdominal injuries in train run-overs. Train run-over had a a longer hospital LOS, more bilateral amputations with large tissue destruction requiring major extension of amputation, and they also developed more complications.

All but 3 patients needed urgent amputations when presenting to the ED, while the 3 others had their amputations delayed due to severe complications in the mangled extremities and/or by-pass obstruction after an initial attempt at limb salvage. Consequently, those last three patients had more complications, more operative procedures, and longer hospital LOS than those patients treated with urgent amputation, as is usually the case [14]. Regarding these postoperative complications, the majority of them were related to wound infection, (grade III of the Clavien-Dindo classification), also reported by other studies [5]. Management of these complications required a multidisciplinary approach with participation of plastic, orthopedic, and vascular surgeons.

$11.7 \%$ of patients died, and the main cause of death was hemorrhagic shock, which was not directly related to the LLA but to abdominal visceral injuries and pelvic fractures.

In conclusion, lower limb amputations are rare in civilian trauma, and are the result of high-energy mechanism. LLA are rarely the only injuries present, and not life-threatening. The overall anatomic severity was comparable to that reported from military conflicts, but with a longer hospital LOS and no mortality. However, the mortality rate was higher in the civilian population. The most frequent mechanism was train run-over, which had the highest frequency of bilateral amputations, and no abdominal injuries.

\section{Limitations of the Study}

A limitation of the study is the exclusion of foot amputations. Despite their consideration as major amputations, they usually present as an isolated injuries and are dealt with by the orthopedic surgeons. They are not included in our trauma registry.

\section{Conflict of Interest}

Sanchez-Arteaga A, Lusilla-Lopez L, Zarain-Obrador L, Burneo-Esteves M, Rey-Valcarcel C, Perez-Diaz MD, Turegano-Fuentes $\mathrm{F}$ declare that they have no conflict of interest.

\section{References}

1. Staruch RMT, Jackson PC, Hodson J, Yim G, Foster MA, et al. (2016) Comparing the surgical timelines of military and civilians traumatic lower limb amputations. Ann Med Surg (Lond) 6: 81-86.

2. Brandon W Godfrey, Ashley Martin, Paul J Chestovich, Lee $\mathrm{GH}$, Ingalls NK, et al. (2017) Patients with multiple traumatic amputations: An analysis of operation enduring freedom joint theatre trauma registry data. Injury 48: 75-79.

3. MacKenzie EJ, Bosse MJ (2006) Factors influencing outcome following limb-threatening lower limb trauma: Lessons learned from the Lower Extremity Assessment Project (LEAP). J Am Acad Orthop Surg 14: S205-S210.

4. Penn-barwell JG (2011) Outcomes in lower limb amputation following trauma: A systematic review and meta-analysis. Injury 42: 1474-1479.

5. Kobayashi L, Inaba K, Barmparas G, Criscouli M, Lustenberger T, et al. (2011) Traumatic limb amputations at a level I trauma center. Eur J Trauma Emerg Surg 37: 67-72.

6. Tile M (1996) Acute pelvic fractures: I. Causation and Classification. J Am Acad Orthop Surg 4: 143-151.

7. Dindo D, Demartines N, Clavien PA (2004) Classification of surgical complications: A new proposal with evaluation in a cohort of 6336 patients and results of a survey. Ann Surg 240: 205-213.

8. Jansen JO, Thomas GO, Adams SA, Tai NR, Russell R, et al. (2012) Early management of proximal traumatic lower extremity amputation and pelvic injury caused by improvised explosive devices (IEDs). Injury 43: 976-979.

9. Yaşar E, Tok F, Kesikburun S, Adab AM, Kelle B, et al. (2016) Epidemiologic data of trauma-related lower limb amputees: A single center 10-year experience. Injury 48 : 349-352.

10. Tintle SM, LeBrun C, Ficke JR, Potter BK (2016) What is new in trauma-related amputations. J Orthop Trauma 30: S16-S20.

11. Scerbo MH, Mumm JP, Gates K, Love JD, Wade CE, et al. (2016) Safety and appropriateness of tourniquets in 105 civilians. Prehosp Emerg Care 20: 712-722. 
12. Kauvar DS, Sarfati MR, Kraiss LW (2011) National trauma databank analysis of mortality and limb loss in isolated lower extremity vascular trauma. J Vasc Surg 53: 1598-1603.

13. Barmparas G, Inaba K, Teixeira PG, Dubose JJ, Criscuoli M (2010) Epidemiology of post-traumatic limb amputation: A Na- tional Trauma Databank analysis. Am Surg 76: 1214-1222.

14. Harris AM, Althausen PL, Kellam J, Bosse MJ, Castillo R, et al. (2009) Complications following limb-threatening lower extremity trauma. J Orthop Trauma 23: 1-6. 